\title{
Transposition of the great arteries New technique for anatomical correction
}

\author{
J. AUbERT, A. PANNETIER, J. P. COUVElly, D. UNAL, F. ROUAUlt, \\ AND A. DELARUE
}

From the Unité d'Exploration et de Traitement des Cardiopathies Congenitales, Service de Chirurgie Pédiatrique, C.H.U. Timone Hôpital des Enfants, Marseille, France

SUMMARY We describe a new technique for the correction of transposition of the great arteries by 'detransposition'. An aortopulmonary window is created and a patch placed over this and the coronary ostia so that the coronary arteries arise from the new aorta. Thus, direct surgery on the coronary arteries is avoided with all the complications which may result from this in neonates and infants. A $4.2 \mathrm{~kg}$ infant, with transposition and ventricular septal defect, was successfully operated on using this technique. We discuss the indications for this type of operation and conclude that, until we have more experience, it should be used only in children with a left ventricular pressure at least half systemic.

Early and late complications have been recorded after the Mustard operation for the treatment of transposition of the great arteries (Aberdeen, 1971; El Said et al., 1972; Bonham-Carter, 1973; Champsaur et al., 1973; Clarkson et al., 1972; Sørland et al., 1976). In our experience postoperative arrhythmias now occur very rarely since we have learnt where to sew the patch on the posterior wall of the atria. However, retraction of the patch resulting in stenosis of the venae cavae or pulmonary veins may occur in a proportion of cases for technical reasons (Stark et al., 1974). Furthermore, this type of operation does not result in anatomical correction, and we do not know whether the right ventricle and tricuspid valve can function effectively against systemic resistance for $\mathbf{4 0}$ or more years. For these reasons, and though we think the Mustard operation is a good one, we have been looking for several years for a new surgical technique which will make anatomical correction possible.

It is easy to 'detranspose' the great arteries, but difficult to 'detranspose' the coronary arteries. Two surgical techniques have been suggested to overcome this difficulty. In the first, the coronary arteries are detached from the former aorta, either together or individually (Idriss et al., 1961; Jatene et al., 1976), and reinserted into the new aorta. This type of operation has been attempted in children but with- out much success. Death may result from twisting or kinking of these tiny arteries. The other technique uses an intra-aortic (Planché, 1976) or intratruncal (Carpentier, 1974) patch to bring the coronary ostia into continuity with the new aorta. Unfortunately these techniques have not been used in children, and seem difficult to perform on infants less than 1 year of age.

Experimental transposition surgery is almost impossible in animals since they do not survive with transposition of the great arteries, even after creation of a large atrial septal defect; we have, therefore, worked only on pathological specimens of hearts with $d$-transposition. Our observations have led us to the conclusion that operations requiring transplantation of the coronary ostia are dangerous in infants. In addition, the distance between the origins of the coronary arteries and the posterior artery is sometimes too great for direct anastomosis to be possible. A new approach is, therefore, necessary: one of these is to leave the coronay ostia in place and to create a shunt from the new aorta.

\section{Method}

The first step of our technique is the creation of an aortopulmonary window. This can be done in the usual way as described first by Davidson (1955). The 
coronary flow must then be rerouted from the former pulmonary trunk through the aortopulmonary window to the coronary ostia. This is done by opening the aorta and suturing a Dacron patch to the posterior wall of the aorta, thus creating a tunnel between the coronary ostia and the aortopulmonary window. After this has been done there is still transpostion of the great arteries, but with the coronary arteries arising from the pulmonary trunk (Fig. 1, stages 1-3). The great arteries are then switched: this may be difficult because, as can be observed on pathological specimens, the pulmonary trunk is quite short in $d$-transposition; it is important, therefore, when the aorta and pulmonary trunk are transected not to transect the aorta at too low a level, so that it is possible to suture the proximal end of the aorta to the distal end of the pulmonary trunk. In addition, it is not possible to perform a complete end-to-end anastomosis without incorporating a Dacron or pericardial patch to increase the circumference of the new pulmonary trunk. Furthermore, there is within this new pulmonary trunk a 'diverticulum' forming the origin of the coronary arteries, which may obstruct outflow from the right ventricle (Fig. 1, stages 4-6); the use of a widening patch to reconscruct the new pulmonary trunk will prevent this from causing supravalvar pulmonary stenosis.

\section{Case report}

On 9 November 1976 we operated on a 14-week-old
$4.2 \mathrm{~kg}$ boy with $d$-transposition and a small ventricular septal defect using this technique.

$\mathrm{He}$ was very cyanosed despite previous Rashkind atrioseptostomy. He was treated with digoxin and diuretics for 4 weeks but was still in severe cardiac failure (Fig. 2). The catheterisation data are shown in the Table.

At operation, the temperature was reduced to $25^{\circ} \mathrm{C}$ by surface cooling; cooling was continued on bypass and at $20^{\circ} \mathrm{C}$ the pump was turned off and the heart arrested for 55 minutes for the creation of the aortopulmonary window, the suture of the Dacron patch around the coronary arteries, and the reconstruction of the new aorta. Reconstruction of the pulmonary trunk, using a pericardial gusset, closure of the atrial septal defect, and closure of the ventricular septal defect through the right atrium were done under extracorporeal circulation during rewarming with a flow of $1500 \mathrm{ml} / \mathrm{min}$.

After operation the cardiac output was well maintained (mixed venous saturation over $60 \%$ ), though it was not possible to take the child off the respirator until the 6 th postoperative day. $\mathrm{He}$ was extubated on the 7th postoperative day. Since operation he has been asymptomatic, he has gained weight normally, and requires no digoxin.

\section{Discussion}

This technique makes it unnecessary to operate directly on the coronary arteries, but nevertheless

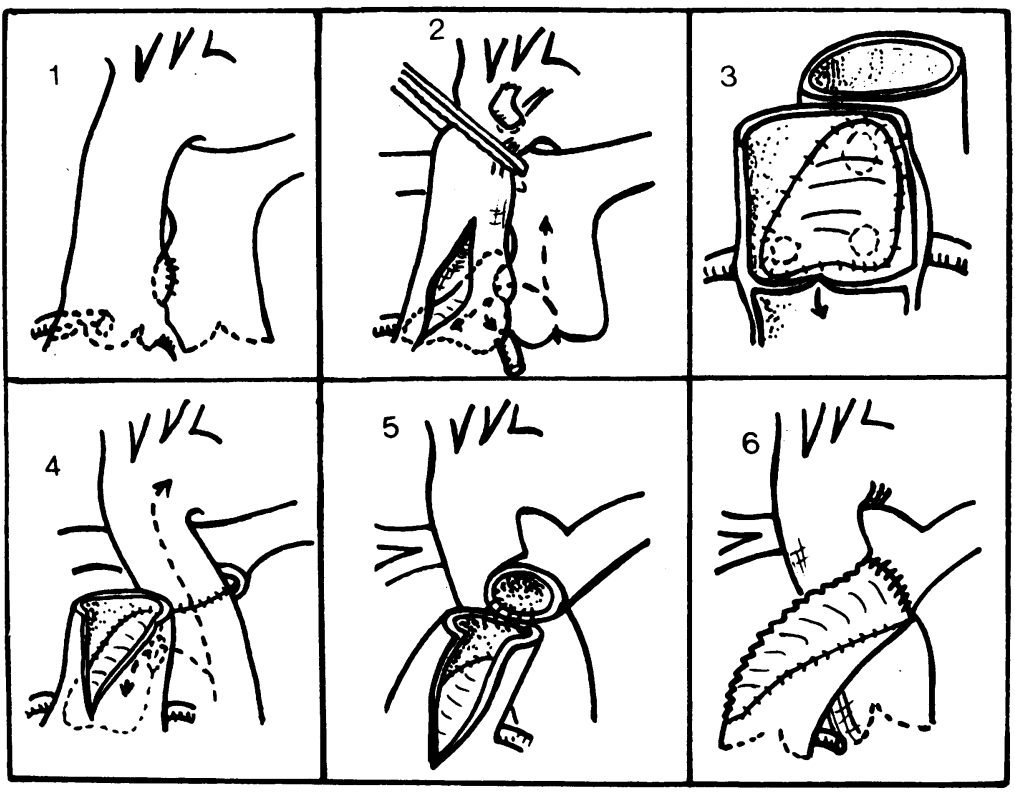

Fig. 1 Stages 1-3 of the operation: creation of aortopulmonary window and placing of patch to form tunnel between new aorta and coronary ostia. Stages 4- 6 of the operation: 'detransposition' of the great arteries completed with incorporation of a Dacron patch into the pulmonary trunk. 


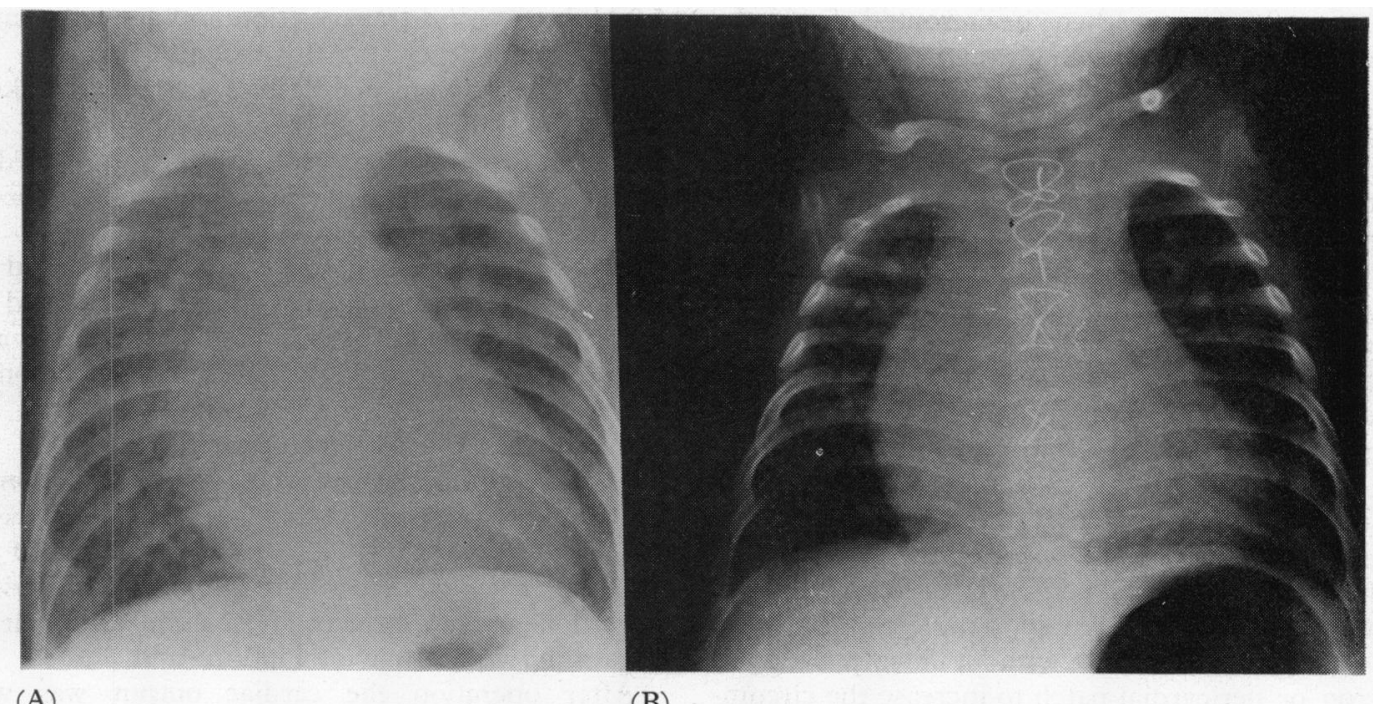

(A)

Fig. 2 (A) Posteroanterior chest $x$-ray film before operation; (B) Posteroanterior chest $x$-ray film 30 days after operation.

Table Haemodynamic data

\begin{tabular}{|c|c|c|c|}
\hline & $\begin{array}{l}\text { Pressure } \\
(m m H g) \\
S \quad D\end{array}$ & Mean & $\begin{array}{l}\text { Oxygen } \\
\text { saturation } \\
(\%)\end{array}$ \\
\hline $\begin{array}{l}\text { SVC } \\
\text { RA } \\
\text { RV } \\
\text { Ao } \\
\text { PV } \\
\text { LA } \\
\text { LV } \\
\text { PA }\end{array}$ & $\begin{array}{rr}80 & 0 \\
80 & 55 \\
& \\
40 & 0 \\
40 & 10\end{array}$ & $\begin{array}{r}2 \\
30 \\
65 \\
2 \\
2 \\
21 \\
18\end{array}$ & $\begin{array}{l}40 \\
41 \\
50 \\
50 \\
96 \\
92 \\
85 \\
85\end{array}$ \\
\hline
\end{tabular}

poses problems. In the first place, the operation is a long one, during the course of which we have to create an aortopulmonary window, suture a patch inside the ascending aorta, and perform two vascular anastomoses, one incorporating a patch to widen the pulmonary trunk. Finally, we have to close the atrial and ventricular septal defects. The duration of extracorporeal circulation was 110 minutes in our first operation but with more experience it should be possible to reduce this to 60 to 90 minutes.

The mode of origin of the coronary arteries may pose another technical problem. The anatomy of the coronary arteries in transposition has been well described by Lev (1953), Rowlatt (1962), Shaher and Puddu (1966), and Vlodaver et al. (1975). This operation is simplest when there is only one coronary ostium, as in 4 per cent of cases (Rowlatt, 1962). The usual situation, in which there are two coronary ostia arising from the posterior and left aortic sinuses, as in our case, does not present too many difficulties for the surgeon, but we prefer to detach the commissure between the two aortic sinuses so the patch will not have to be shaped around the coronary ostia and the commissure. In this way a tricuspid semilunar valve is changed into a bicuspid one, in what is now the pulmonary position. This may be thought to be 'destructive' and not 'constructive' surgery, but is not necessarily harmful. Thus, in some patients with tetralogy of Fallot we may create pulmonary regurgitation when a patch has to be placed across the pulmonary ring; despite this, the clinical progress of these children is usually satisfactory. We preferred to use a Dacron rather than a pericardial patch to create the tunnel because of the risk that a pericardial patch would ultimately retract. The future of the child depends on the fate of the pouch over the coronary ostia and aortopulmonary window. A very large aortopulmonary window made using interrupted stitches is desirable but may be difficult to create because of the high origin of the coronary arteries and the low origin of the right pulmonary artery in transposition.

The reconstruction of the new pulmonary trunk must be accomplished if possible by direct anastomosis of the posterior wall of this vessel, with interrupted stitches in order to allow for growth of the pulmonary artery and thus avoid later reoperation. If this is not possible a Dacron tube may be interposed as in the technique described by Jatene et al. (1976).

The indications for this operation have yet to be 
established. Though we would like to use this new technique for all patients with transposition, we do not at present ccnsider it for children with a low left ventricular pressure, as we do not know how a left ventricle which is used to ejecting into a low resistance system will react when suddenly called upon to eject into a high resistance vascular bed. We have yet to learn if a 6- to 9-month-old child, with simple transposition and low left ventricular pressure, will tolerate anatomical correction. Prolonged circulatory assistance after correction, and the use during the postoperative period of inotropic drugs together with a vasodilator agent, such as nitroprusside, may be the answer to the problem, but more research is needed before the technique can be applied to this group of patients.

We suggest that this procedure should be used in preference to a palliative Mustard operation (Lindesmith et al., 1972; Bernhard et al., 1976; Mair et al., 1976) in patients with a high pulmonary vascular resistance. Our second indication would be, as in our first clinical case, transposition with ventricular septal defect in infants less than 6 months of age. The mortality rate with a Mustard procedure has been relatively high in these cases in the experience of all surgeons and we think that this new operation is preferable to a Mustard procedure or pulmonary artery banding.

The operation may also be appropriate in the few newborn infants with simple transposition in whom there is no improvement after Rashkind atrioseptostomy; in these cases the Blalock-Hanlon operation may also be ineffective and the mortality of the Mustard procedure is high. In newborn infants with simple transposition left ventricular pressure is almost at systemic level while there is high (fetal) pulmonary vascular resistance; because the pulmonary vascular resistance and therefore left ventricular pressure falls during the first few days or weeks of life, we should operate very early in life in these children. However, we hesitate to use this new operation until we have had more experience with the technique and have more information about the safety of prolonged cardiopulmonary bypass in the newborn.

Though excellent overall results are obtained now with the Mustard operation in simple transposition (Mustard, 1974), this operation does not give as good results in infants with transposition and ventricular septal defect. In addition, it does not provide the child with an anatomical correction, which requires that the left ventricle must be the systemic ventricle. For these reasons and because of anatomical problems posed by 'detransposition' of the coronary arteries if Jatene's operation is used, we have tried another approach for anatomical correction of transposition. We still do not know what late complications may occur but think that our new operation may provide a logical solution to this difficult problem.

\section{Addendum}

Since this paper was submitted for publication we have operated on 3 more patients, with 1 survival and 2 deaths (at 12 and 36 hours after operation) resulting from coronary stenosis. We now use homograft aortic wall preserved in Hancks's solution in place of Dacron for the intra-aortic patch.

\section{References}

Aberdeen, E. (1971). Correction of uncomplicated cases of transposition of the great arteries. British Heart fournal, 33, Suppl. 66-68.

Bernhard, W. F., Dick, M., II, Sloss, L. J., Castaneda, A. R., and Nadas, A. S. (1976). The palliative Mustard for double outlet right ventricle or transposition of the great arteries with ventricular septal defect, pulmonary arterial hypertension and pulmonary vascular obstructive disease. Circulation, 54, 810-816.

Bonham-Carter, R. E. (1973). Progress in the treatment of transposition of the great arteries. British Heart fournal, 35 573-577.

Carpentier, A. (1974). La transposition complète des gros vaisseaux. Une nouvelle operation pour son traitement. Nouvelle Presse Médicale, 3, 2416-2417.

Champsaur, G. L., Sokol, D. M., Trusler, G. A., and Mustard, W. T. (1973). Repair of transposition of the great arteries in 123 pediatric patients. Circulation, 47, 1032-1041.

Clarkson, P. M., Barratt Boyes, B., Neutze, J. M., and Lowe, J. B. (1972). Results over a ten year period of palliation followed by corrective surgery for transposition of the great arteries. Circulation, 45, 1251-1258.

Davidson, J. S. (1955). Anastomosis between the ascending aorta and the main pulmonary artery in the tetralogy of Fallot. Thorax, 10, 348-351.

El-Said, G., Rosenberg, H. S., Mullins, C. E., Hallman, G. L., Cooley, O. A., and McNamara, O. C. (1972). Dysrythmias after Mustard's operation for transposition of the great arteries. American fournal of Cardiology, 30, 526-532.

Idriss, F. S., Goldstein, I. R., Grana, L., French, D., and Potts, W. J. (1961). A new technic for complete transposition of the great vessels. Circulation, 24, 5-11.

Jatene, A. D., Fontes, V. F., Paulista, P. P., Souza, L. C. B., Neger, F., Galantier, M., and Sousa, J. E. M. R. (1976). Anatomic correction of transposition of the great vessels. Fournal of Thoracic and Cardiovascular Surgery, 72, 364-370.

Lev, M. (1953). Autopsy Diagnosis of Congenitally Malformed Heart. Charles C. Thomas, Springfield, Illinois.

Lindesmith, G. G., Stiles, O. R., Tucker, B. L., Gallagher, M. E., Stanton, R. E., and Meyer, B. W. (1972). The Mustard operation as a palliative procedure. Fournal of Thoracic and Cardiovascular Surgery, 63, 75-80.

Mair, D. D., Ritter, D. G., Danielson, G. R., Wallace R. B., and McGoon, D. C. (1976). The palliative Mustard operation: rationale and results. American fournal of Cardiology, 37, 762-768.

Mustard, W. T. (1974). Successful two stage correction of transposition of the great arteries. Surgery, 55, 469-472.

Planché, C. (1976). La transposition des gros vaisseaux. 
Étude experimentale d'un nouveau procédé de détransposition à l'étage vasculaire. Nouvelle Presse Médicale, 5, 1991-1992.

Rowlatt, U. F. (1962). Coronary artery distribution in complete transposition. Fournal of the American Medical Assnciation, 179, 269-278.

Shaher, R. M., and Puddu, G. C. (1966). Coronary arterial anatomy in complete transposition of the great vessels. American fournal of Cardiology, 17, 355-361.

Sørland, S. J., Tjønneland, S., and Hall, K. V. (1976). Transposition of great arteries. British Heart fournal, 38, 584-588.

Stark, J., Silove, E. D., Taylor, J. F., and Graham, G. R.
(1974). Obstructive to systemic venous return following the Mustard operation for transposition of the great arteries. Fournal of Thoracic and Cardiovascular Surgery, 68, 742-749.

Vlodaver, Z., Neufeld, H. N., and Edwards, J. E. (1975). Coronary Arterial Variations in the Normal Heart and in Congenital Heart Disease. Academic Press, London.

Requests for reprints to $\mathrm{Dr}$ J. Aubert, Service de Chirurgie Pédiatrique, C.H.U. Timone Hôpital des Enfants, Boulevard Jean-Moulin 13005, Marseille, France.

We regret that as a result of circumstances beyond our control publication of the last issue of Volume 39 and the first two issues of the current volume have been delayed. 